\title{
Implante imediato pós-exodontia em região de molar utilizando um novo implante com a técnica de preparo intrarradicular e preservação alveolar
}

\section{Immediate post-extraction implant in the molar region using a new implant with the technique of intraradicular preparation and alveolar preservation}

\section{Implante post-extracción inmediata en la región molar utilizando un nuevo implante con la técnica de preparación intrarradicular y preservación alveolar}

Sérgio Henrique Lago Martins iD

Gustavo Henrique Apolinário Vieira ${ }^{1}$

Fabio Jose Barbosa Bezerra (iD)

Bruna Ghiraldini iD

Sérgio Luís Scombatti de Souza iD

1 gustavohav@gmail.com

Endereço para correspondência:

Sérgio Henrique Lago Martins

Faculdade de Odontologia de Ribeirão Preto - USP

Departamento de Cirurgia e Traumatologia Buco-Maxilo-Facial e Periodontia

Avenida do Café, s/n - Campus da USP

14040-904 - Ribeirão Preto - São Paulo - Brasil

E-mail: sergiolagom@gmail.com

Recebido: 07.09.2020

Aceito: 28.09.2020

\section{RESUMO}

Exodontias em dentes posteriores tendem a ser negligenciadas por não estarem em área estética, resultando em maior perda tecidual pós extração. Ao lançar mão de abordagens imediatas há uma redução significativa nas reabsorções dos tecidos remanescentes, promovendo maior estabilidade nas reabilitações implantossuportadas no que se refere à altura da margem gengival, evitando coroas protética com sobrecontorno. $\mathrm{O}$ implante imediato associado a enxertia óssea pode ser uma opção viável na manutenção da arquitetura óssea. Assim, o objetivo deste relato é apresentar as vantagens da utilização de um novo implante com macro e nanoestrutura favoráveis à instalação imediata, em um caso clínico em região posterior de mandíbula. Paciente do gênero feminino, 42 anos de idade, sem comprometimento sistêmico compareceu à clínica odontológica para reabilitação da região do dente 46 com implante dentário, devido a destruição coronária. Optou-se pela instalação de um implante alta estabilidade primária (Epikut Plus ${ }^{\circledR}$, S.I.N. Implant System, São Paulo, Brasil) associado a preenchimento do gap com enxerto ósseo xenógeno e selamento do alvéolo com cicatrizador em polímero termoplástico orgânico personalizável. 
Em um pós-operatório de 30 dias observou-se boa cicatrização tecidual e ganho de tecido queratinizado. O controle pósoperatório de 2 meses mostrou que houve uma perfeita manutenção tecidual, possibilitando um tecido gengival de qualidade para condicionamento da mucosa peri-implantar durante o período de provisionalização. Após 3 meses de tratamento foi solicitada radiografia periapical e confeccionada prótese parafusada sobre o implante. O implante com características adequadas permitiu o uso de técnica imediata à exodontia, com ótima estabilidade primária proporcionada pela macrogeometria, e formação óssea precoce devido à superfície nanoestruturada. Este conjunto de fatores possibilitaram uma reabilitação oral bem-sucedida em espaço de tempo reduzido.

PALAVRAS-CHAVE: Implantes dentários. Materiais biocompatíveis. Carga imediata em implante dentário.

\begin{abstract}
Tooth extraction is inevitably accompanied by a resorption in the alveolar crest. Procedures on condemned teeth in the posterior region tend to be neglected because they are not in an aesthetic area, resulting in greater tissue loss after tooth extraction. By using immediate approaches, there is a significant reduction in the reabsorption of the remaining tissues, promoting greater stability in implant-supported rehabilitation with regard to the height of the gingival margin and avoiding prosthetic crowns with over-contour. Among them, the immediate implant associated with bone grafting may be a viable option for maintaining bone architecture. Thus, the objective of this case report is to present the advantages of using implants with macrostructure favorable to the immediate installation of implants in the posterior region of the mandible. Female patient, 42 years old, without systemic involvement, attended the dental clinic for rehabilitation of the region of tooth 46 with dental implant, due to coronary destruction. We opted for the installation of an implant with high primary stability (Epikut Plus ${ }^{\circledR}$, S.I.N. Implant System, São Paulo, Brazil), associated with filling the gap with xenogenous bone graft and sealing the alveolus with a polymer-based customized healing abutment. In a 30-day postoperative period, good tissue healing and keratinized tissue gain were observed. In a 2-month postoperative control, the tissue quality provided perfect tissue maintenance, enabling a quality soft tissue for conditioning the peri-implant mucosa during the provisionalization period. After 3 months of treatment, a periapical radiograph was requested and a screwed prosthesis was made over the implant. Through the proposed technique it was possible to guarantee the implant installation immediately after tooth extraction with good primary stability provided by the implant macrogeometry and shorten the healing time due to the bioactivity of the HAnano coating.
\end{abstract}

KEYWORDS: Dental implants. Biocompatible materials. Immediate dental implant loading.

\title{
RESUMEN
}

Las extracciones en dientes posteriores tienden a descuidarse porque no se encuentran en el área estética, lo que resulta en una mayor pérdida de tejido después de la extracción. Mediante el uso de abordajes inmediatos se produce una reducción significativa de la reabsorción de los tejidos remanentes, promoviendo una mayor estabilidad en las rehabilitaciones implantosoportadas respecto a la altura del margen gingival, evitando coronas protésicas con sobrecontorno. La implantación inmediata asociada con el injerto óseo puede ser una opción viable para mantener la arquitectura ósea. Así, el objetivo de este informe es presentar las ventajas de utilizar un nuevo implante con macro y nanoestructura favorable a la instalación inmediata, en un caso clínico en la región posterior de la mandíbula. Paciente de sexo femenino, 42 años, sin afectación sistémica, que acude a la consulta odontológica para rehabilitación de la región del diente 46 con implante dental, por destrucción coronaria. Optamos por la instalación de un implante de alta estabilidad primaria (Epikut Plus ${ }^{\circledR}$, S.I.N. Implant System, São Paulo, Brasil) asociado al llenado del hueco con injerto óseo xenógeno y sellado del alvéolo con un curador en un polímero termoplástico orgánico personalizable. En un postoperatorio de 30 días se observó una buena cicatrización del tejido y una ganancia de tejido queratinizado. El control postoperatorio a los 2 meses mostró un perfecto mantenimiento del tejido, lo que permitió que el tejido gingival de calidad acondicionara la mucosa periimplantaria durante el período de provisionalización. A los 3 meses de tratamiento se solicitó una radiografía periapical y se realizó una prótesis atornillada sobre el implante. El implante con características adecuadas permitió el uso de una técnica de extracción inmediata, con excelente estabilidad primaria proporcionada por macrogeometría, y formación ósea temprana debido a la superficie nanoestructurada. Este conjunto de factores permitió una rehabilitación bucal exitosa en poco tiempo.

PALABRAS CLAVE: Implantes dentales. Materiales biocompatibles. Carga imediata del implante dental. 


\section{INTRODUÇÃO}

O tratamento reabilitador com implantes osseointegráveis é uma alternativa eficiente na substituição de dentes que foram perdidos. Vale ressaltar que o uso dos implantes osseointegráveis tem cada vez mais ganho destaque na Odontologia, pela capacidade de restabelecer a função mastigatória, estética e melhoras na qualidade de vida dos pacientes ${ }^{1}$.

Conforme a terapia com implantes evolui, novos desafios são enfrentados como resultado de maiores demandas funcionais e estéticas. Os protocolos originais durante o final dos anos 1970 e 1980 defendiam a instalação de implantes dentários exclusivamente em sítios completamente cicatrizados. Além disso, um período de cicatrização submersa de 6 a 12 meses antes do carregamento era recomendado ${ }^{2}$.

Felizmente, como consequência de pesquisas contínuas, novas tecnologias de superfície e novos designs de implantes, os protocolos mais recentes geraram redução nos intervalos de tempo por meio de instalação imediata de implantes e/ou carga imediata ou precoce. Embora diferentes definições tenham sido propostas para instalação de implantes como imediata, precoce e convencional, em 2004, Hämmerle e colaboradores descreveram 4 protocolos diferentes para instalação de implantes após a exodontia: o tipo 1 refere-se a implantes instalados imediatamente após a extração do dente; o tipo 2 é considerado quando os implantes são instalados após 4 a 8 semanas, alcançando a cobertura completa com tecido mole; o tipo 3 consiste em implantes instalados após 12 a 16 semanas quando ocorre preenchimento clínico e / ou radiográfico substancial com osso; o tipo 4 refere-se a implantes colocados em sítios cicatrizados ${ }^{3}$.

A instalação de implantes imediatos é uma abordagem terapêutica introduzida em 1976 como uma alternativa à colocação tardia clássica descrita por Branemark ${ }^{4}$. Esta alternativa de tratamento oferece várias vantagens, como redução no tempo de tratamento e no número de intervenções cirúrgicas, elevando assim a satisfação do paciente. Além dessas vantagens, as taxas de sobrevivência e sucesso dos implantes imediatos têm mostrado resultados favoráveis, semelhantes aos implantes instalados em rebordos cicatrizados. Uma revisão sistemática sobre implantes instalados imediatamente após a extração dentária demonstrou taxas de sobrevivência de mais de 98\% após um acompanhamento mínimo de 1 ano $^{4}$. Estes resultados são comparáveis à colocação de implantes convencionais em locais cicatrizados, que mostraram taxas de sobrevivência em 5 anos de até $95 \%{ }^{5}$. Tais resultados estão de acordo com um ensaio clínico controlado randomizado que demonstrou cicatrização adequada de tecidos moles e duros com níveis de osso marginal estáveis após 3 anos de acompanhamento para implantes imediatos instalados na região anterior ${ }^{6}$. As vantagens estéticas de implantes imediatos com carga imediata em pacientes que perderam dentes anteriores tornam-se óbvias quando o tempo de tratamento é reduzido, diminuindo o período de espera de entrega de uma restauração fixa. No entanto, instalação de implantes em áreas posteriores também pode representar uma abordagem benéfica, que proporciona uma recuperação mais rápida da função mastigatória ${ }^{4}$.

Os resultados relatados na literatura mostraram alta sobrevivência $(99.1$ - 100\%) e taxas de sucesso (93.9 $100 \%$ ) para implantes instalados em alvéolos de extração em áreas posteriores. Da mesma forma, uma revisão sistemática publicada em 2010 relatou uma taxa de sobrevivência de até $99 \%$ para implantes colocados em áreas posteriores ${ }^{6-10}$. Outra revisão sistemática recente ${ }^{4}$ relatou que, em cenários selecionados, a instalação de implantes imediatos em região de molar pode ser considerada uma técnica previsível, evidenciada por uma alta sobrevivência e taxa de sucesso dos implantes, com perda óssea marginal mínima. $\mathrm{O}$ protocolo de tratamento ideal consiste em abordagem sem retalho, colocação de implante em um estágio, sem realização de carga imediata, enxertia de gap e utilização de implantes com diâmetro $<5 \mathrm{~mm}$.

A presença do osso adjacente à superfície do implante é determinada pela técnica cirúrgica e também pelo material do implante, pelo desenho ou macrogrometria e textura superficial ou micro e nanogeometria. Pode-se associar a estabilidade óssea do implante às características e texturas de suas superfícies. Portanto, a osseointegração ótima depende das características do material que é constituído o implante, a capacidade do implante suportar cargas, a técnica cirúrgica utilizada e o tipo ósseo presente no local da inserção do implante. A longo prazo, isso também depende do desenho da prótese, carregamento oclusal e manutenção dos tecidos periimplantares livres de placa ou inflamação ${ }^{11}$.

A macrogeometria do implante também afeta diretamente a sua estabilidade primária. Evoluções têm sido propostas na geometria dos implantes, como também em suas superfícies, buscando maior previsibilidade e redução do tempo de tratamento, uma vez que implantes com tratamento de superfície são relacionados a uma maior taxa de sobrevivência quando comparados a implantes sem tratamento $^{12}$.

Assim, a utilização de implantes com macroestrutura que proporcionem uma maior estabilidade primária, e uma microestrutura que favoreça o rápido reparo ósseo, é especialmente indicada na reabilitação com implantes dentários em áreas de baixa qualidade óssea, principalmente em técnica de instalação imediata à exodontia. Nesse contexto, este relato objetiva mostrar um caso clínico em que foi utilizado um novo implante, com macro e nanogeometria otimizadas para o uso em técnicas de instalação imediata à extração, na reabilitação oral em região posterior de mandíbula. 


\section{RELATO DE CASO}

Paciente do gênero feminino, 45 anos de idade, não fumante e com boa saúde sistémica, apresentou-se a? clínica particular relatando desconforto no dente 46 , buscando receber tratamento com implante osseointegrável. Durante o exame clínico, foi observado dente com grande destruição coronária (Figura 1). A paciente apresentava um bom controle de biofilme bacteriano (índice de placa menor que $20 \%$ ), ausência de sangramento gengival e boa faixa de mucosa queratinizada.

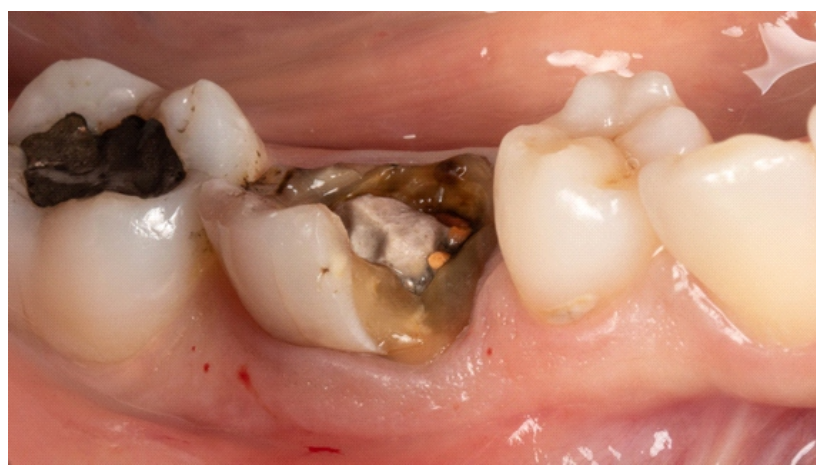

Figura 1 - Aspecto clínico inicial.

Ao exame tomográfico (Figura 2) foi observada presença de tratamento endodôntico e proximidade com área de bifurcação, tornando o prognóstico do dente desfavorável. Foi planejada então exodontia minimamente invasiva com instalação de implante imediato, devido à disponibilidade de tecido na região de septo ósseo, favorecendo a possibilidade de instalação imediata.

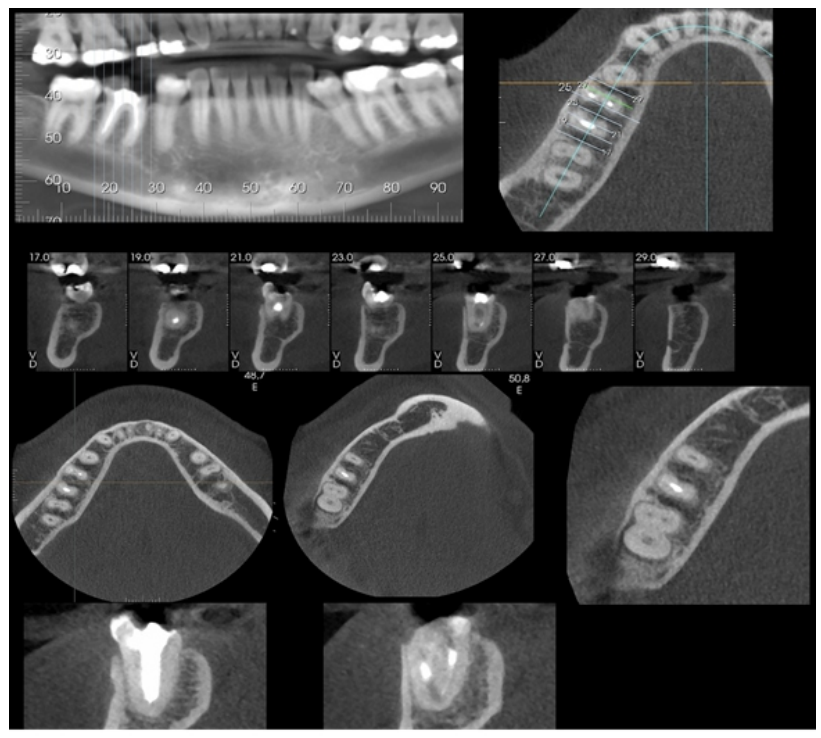

Figura 2 - Tomografia inicial.
A paciente foi informada de todas as etapas do tratamento, assinou o Termo de Consentimento Livre e Esclarecido para autorização dos procedimentos necessários, assim como para toda a documentação e divulgação científica do caso, preservando a sua identidade.

Após antissepsia extra-oral e bucal, foi realizada uma anestesia local infiltrativa com cloridrato de articaína e epinefrina $(72 \mathrm{mg} / 1.8 \mathrm{ml}+0.018 \mathrm{mg} / 1.8 \mathrm{ml}$, DFL Indústria e Comércio S.A.). Depois disso, iniciou-se o processo de fresagem sem a exodontia prévia do dente, para facilitar a localização do correto posicionamento tridimensional do implante, com a utilização das fresas tipo lança, Helicoidal 2.0, Helicoidal 2.7, Helicoidal 3.3, Helicoidal 4.1 (Figura 3). Após a fresagem, foi realizada a odontossecção para remoção atraumática das raízes mesial e distal, com a utilização de periótomos flexíveis e alavancas de Heidbrink, e após a exérese do remanescente radicular realizou-se uma irrigação copiosa do alve?olo com a utilização de soro fisiológico $0.9 \%$ (Figura 4), para iniciar a inserção do implante (Epikut Plus, S.I.N. Implant System, São Paulo, Brasil) com microsuperfície revestida por hidroxiapatita em escala nanométrica (HAnano, Promimic, Gotemburgo, Suécia) com dimensões de 4.5 X $10 \mathrm{~mm}$ (Figura 5). O implante, após instalado e em sua posição final, apresentou boa estabilidade prima?ria e travamento inicial de $40 \mathrm{Ncm}$ (Figura 6).

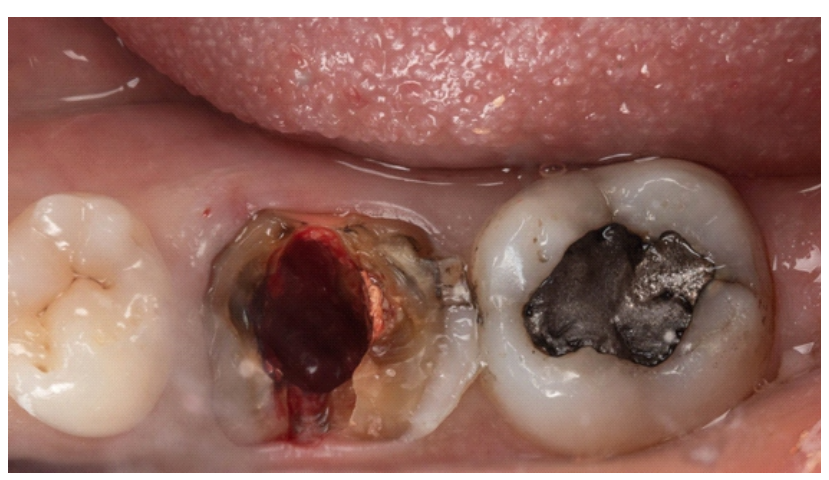

Figura 3 - Técnica de fresagem com o dente para facilitar a localização do correto posicionamento tridimensional.

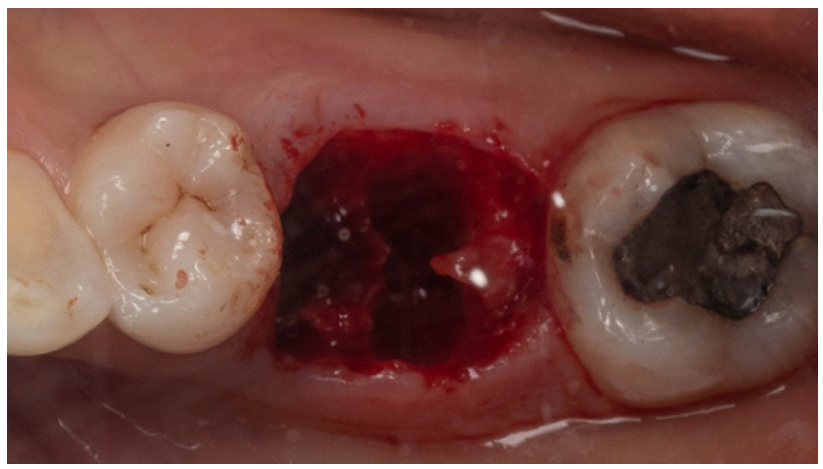

Figura 4 - Vista após exodontia, apresentando a marca da perfuração. 


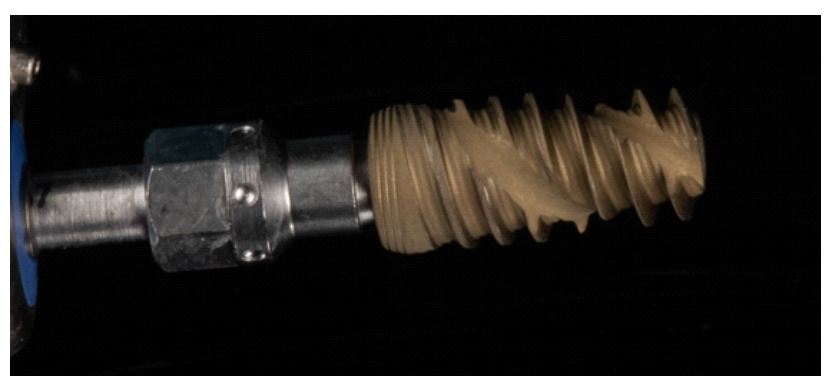

Figura 5 - Implante com dimensões de 4.5 X 10 mm.

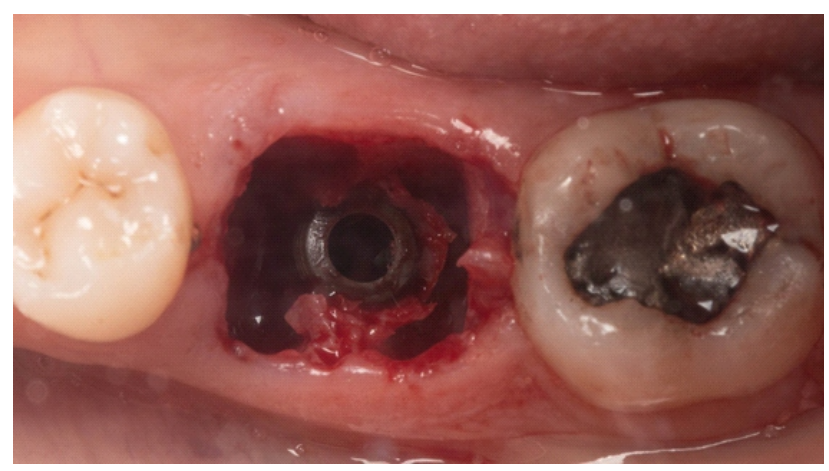

Figura 6 - Implante inserido na correta posição 3D.

Depois da inserção do implante foi realizado o preenchimento do gap ósseo mesial e distal com a utilização de enxerto ósseo xenógeno inorgânico Bonefill Mix ${ }^{\circledR}$ (Bionnovation, Brasil) (Figura 7), e após a condensação do enxerto parafusou-se o cicatrizador personalizável em polímero termoplástico orgânico de poli (éter-éter-cetona) - Peek (S.I.N. Implant System, São Paulo, Brasil) (Figura 8) com diâmetro de perfil de $8 \mathrm{~mm}$ por $4 \mathrm{~mm}$ de altura. Na superfície do cicatrizador foi aplicado adesivo e realizadas pequenas marcações com o objetivo de aumentar as áreas retentivas; logo em seguida, o espaço horizontal entre o cicatrizador e a margem gengival foi preenchido com a resina flow, mantendo todo o contorno gengival original da região (Figura 9).

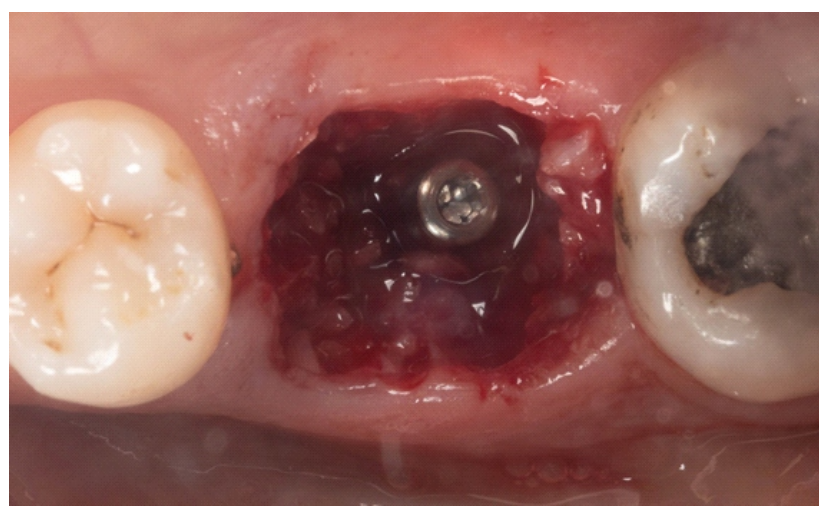

Figura 7 - Preenchimento do gap da região da raiz mesial e distal com enxerto ósseo xenógeno inorgânico Bonefill Mix ${ }^{\circledR}$ (Bionnovation, Brasil).

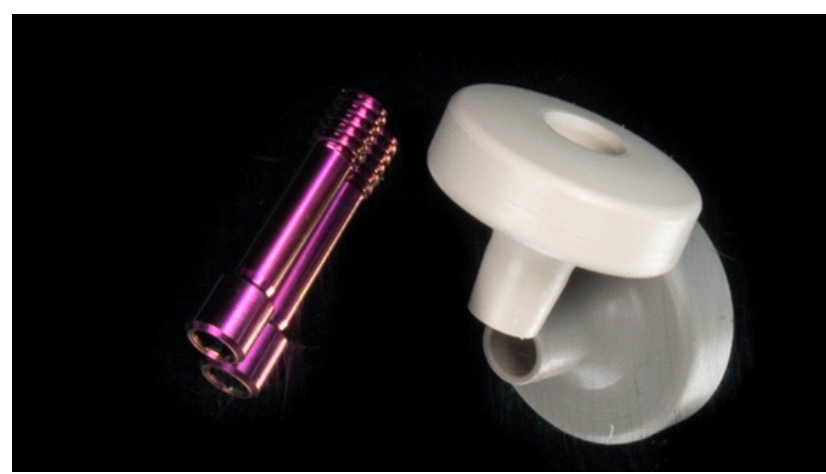

Figura 8-Cicatrizador Peek $(8.0$ X $4.0 \mathrm{~mm})$.

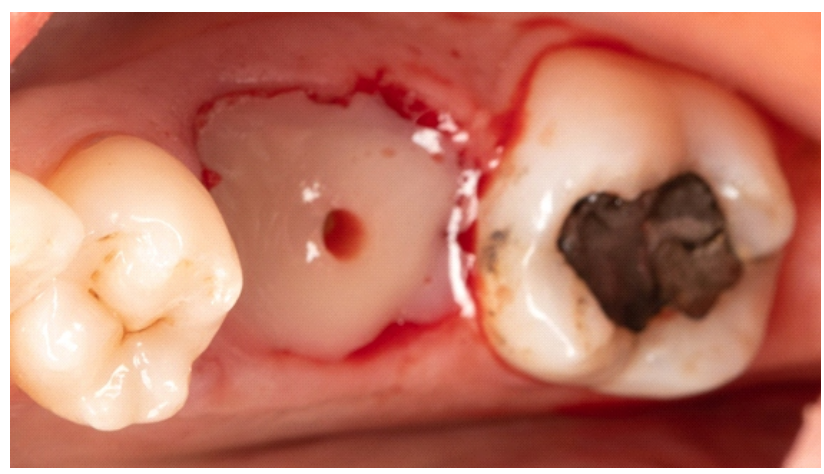

Figura 9 - Pós-operatório imediato.

Foi realizado controle clínico e radiográfico com 48 horas, no qual se constatou boa cicatrização dos tecidos moles e adequado posicionamento do implante (Figuras 10 e 11). Com 15 dias foi realizado novo controle, evidenciando excelente cicatrização dos tecidos periimplantares na região operada (Figura 12). Após 4 meses, uma nova radiografia mostrou ótima formação óssea ao redor do implante (Figura 13). O caso foi finalizado com a instalação de uma prótese do tipo parafusada após 140 dias da realização da cirurgia (Figura 14).

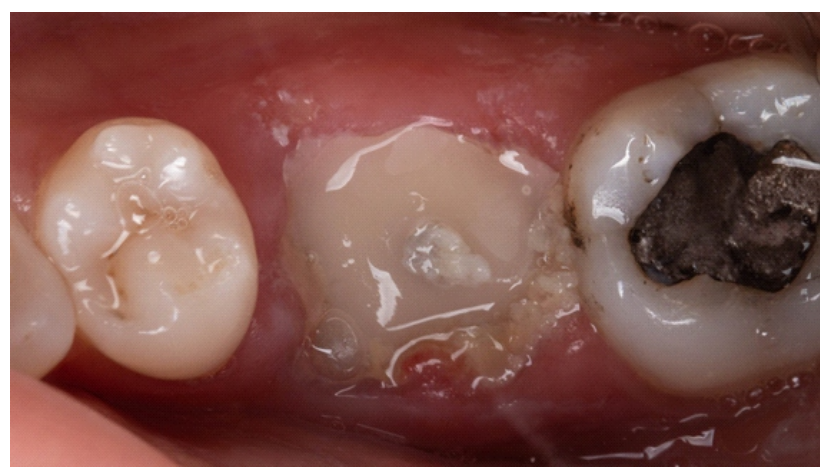

Figura 10 - Pós-operatório de 48 horas. 


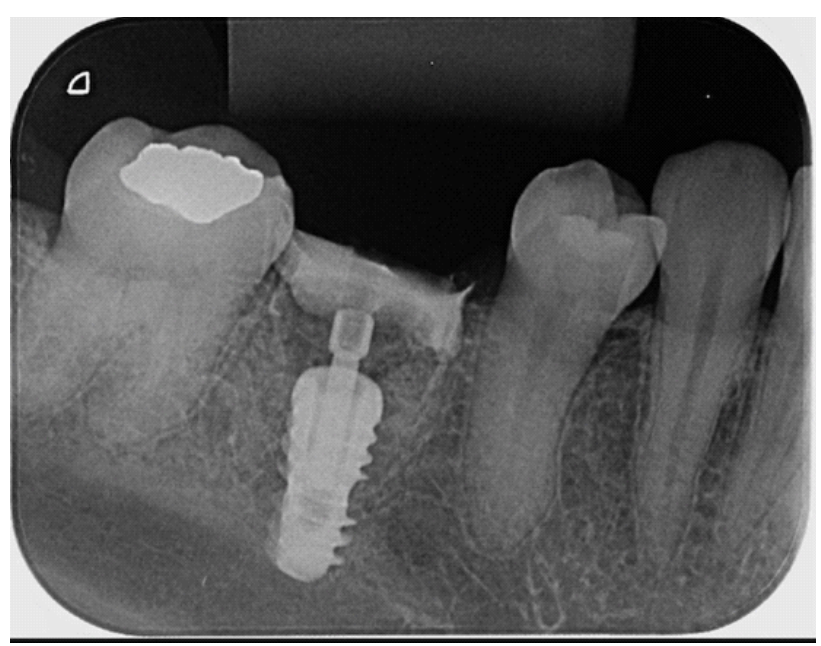

Figura 11 - Aspecto radiográfico de 48 horas.

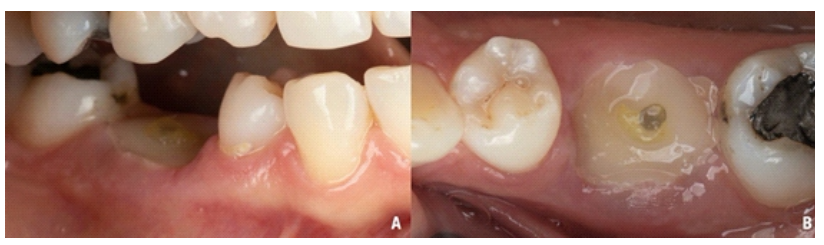

Figura 12 - Pós-operatório de 15 dias. (A) vista vestibular; (B) vista oclusal.

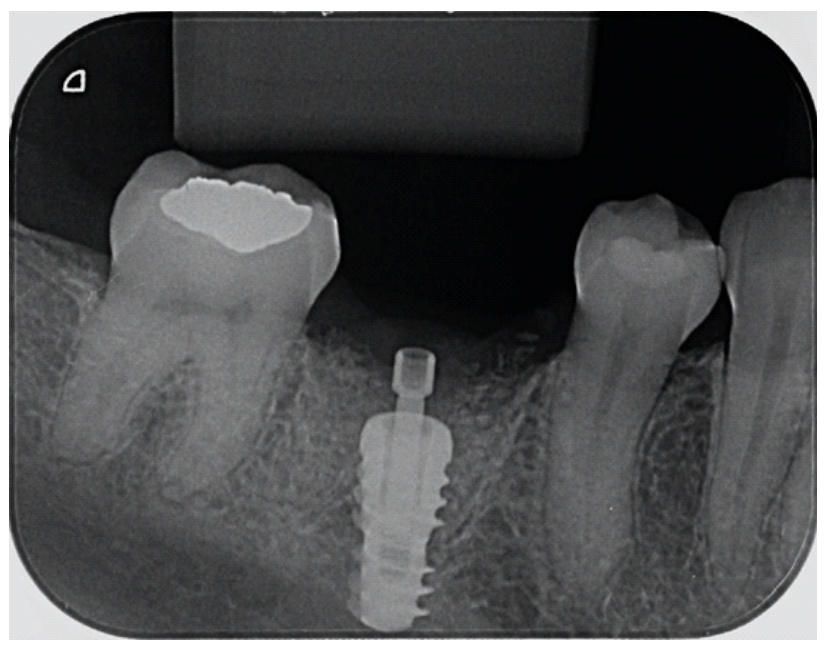

Figura 13 - Aspecto radiográfico 4 meses pós-instalação do implante.

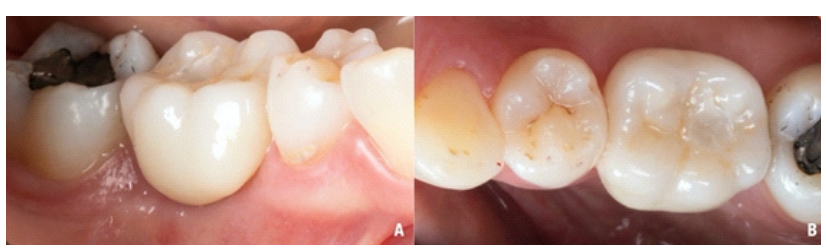

Figura 14 - Aspecto clínico final. (A) vista vestibular; (B) vista oclusal.

\section{DISCUSSÃO}

A instalação de implantes imediatos na área estética é um tema extensamente discutido na literatura; entretanto, nas regiões onde esta demanda é diminuída, os relatos são escassos. A região posterior pode ser desafiadora devido às diferenças entre o tamanho do implante e do alvéolo pósexodontia, comprimento das raízes, altura do tronco radicular e sua divergência, além da qualidade óssea presente, fatores estes que podem complicadores da terapia.

Uma recente revisão sistemática sobre o tema evidenciou que vinte estudos forneceram informações sobre a taxa de sobrevivência, com uma amostra total de 1.106 implantes. A taxa de sobrevivência média ponderada de implantes imediatos após 1 ano de acompanhamento foi de $96.6 \%$, e a taxa de sucesso foi de $93.3 \%$. Os autores concluíram que a colocação imediata do implante no alvéolo de extração do molar pode ser considerada uma técnica previsível, conforme demonstrado por altas taxas de sobrevivência e sucesso, com perda óssea marginal mínima ${ }^{4}$.

Os resultados favoráveis nos procedimentos de implante dependem de muitas variáveis, incluindo características do paciente, técnica cirúrgica e design do implante ${ }^{13}$. Outra característica importante é o valor do torque de inserção, também conhecido como medição da resistência ao corte, para avaliar a densidade óssea durante a cirurgia de implante $^{14}$. O torque de inserção é um parâmetro mecânico influenciado pelo procedimento cirúrgico, desenho do implante e qualidade óssea. Um alto torque de inserção final significa que o implante está firmemente embutido no osso e mecanicamente estável em sua posição definitiva de instalação. A estabilidade medida no momento da instalação do implante é chamada de estabilidade primária, e após a finalização do processo de osseointegração, é denominada estabilidade secundária. Tradicionalmente, uma alta estabilidade primária está associada à expectativa de boa estabilidade secundária, o que garantiria a probabilidade de sucesso do implante e osseointegração ${ }^{15}$.

A macroestrutura do implante influencia fortemente sua estabilidade primária. Os implantes cônicos ou híbridos têm alcançado maior estabilidade primária e valores de torque de inserção. Já quando os implantes cilíndricos são utilizados, estes necessitam de um maior diâmetro para a obtenção dessa maior estabilidade ${ }^{15-16}$. No caso clínico aqui apresentado, o novo implante, com macro e nanoestruturas otimizadas, mostrou favorecer alta estabilidade primária, mesmo em caso de implante imediato em alvéolo de molar. Além disso, sua superfície de escala nanométrica possibilitou a rápida neoformação óssea ao redor do implante, atingindo a estabilidade secundária em tempo precoce, o que permitiu a realização dos procedimentos clínicos para a reabilitação definitiva após 3 meses, diminuindo o tempo de tratamento e traduzindo-se em 
vantagem clínica para o paciente.

A técnica de perfuração óssea interradicular antes da extração dentária pode ser considerada uma modificação simples, mas útil para o procedimento de perfuração padrão ${ }^{17}$. São indicações para essa técnica a presença de remanescente ósseo suficiente para permitir a abordagem, ausência de infecção e integridade das raízes ${ }^{18}$. Já as contraindicações são a mobilidade dentária (em geral devido à grave perda de inserção periodontal), posição radicular desfavorável (como raízes fundidas), anquiloses e infecções ativas ${ }^{18-19}$. É importante ressaltar que, embora a técnica intraradicular possa ser mais simples, facilitando em casos bem indicados a obtenção de uma posição tridimensional correta do implante e um bom torque final de inserção do implante, a preparação interradicular não pode ser considerada uma alternativa ao uso de guias cirúrgicos, mas sim uma possível ferramenta adicional à cirurgia de implante associada a estes aparatos ${ }^{19}$.

Algumas limitações dessa técnica são o aumento da dureza do tecido radicular, que pode resultar em maior tempo clínico e maior risco de aumento da temperatura e de alteração da cicatrização normal, devido aos restos de tecido dentário da perfuração ${ }^{19}$. Com relação a este último ponto, Davarpanah e Szmukler-Moncler fizeram um relato de caso em 5 pacientes: de acordo com os resultados, os resíduos dentais não parecem interferir na osseointegração dos implantes, mas há poucas evidências científicas sobre esse último ponto. Portanto, recomenda-se cautela, com ênfase na irrigação meticulosa e na limpeza cirúrgica ${ }^{20}$. Embora essa técnica seja promissora e a resposta clínica tenha sido favorável durante o manejo intra-operatório e controles pós-operatórios, testes clínicos randomizados controlados são necessários, por meio de método comparativo, para avaliar os benefícios e limitações dessa técnica a longo prazo.

\section{CONCLUSÃO}

A técnica de instalação imediata de implantes representa uma opção potencialmente viável e bastante vantajosa para o paciente, desde que bem indicados, planejados, e cuidadosamente executados. Apresenta taxas de sucesso similares aos dos implantes convencionais, e além disso possibilita a preservação da anatomia alveolar, mantém a altura das cristas ósseas, orienta a angulação de instalação dos implantes e diminui o número de intervenções. Para a obtenção de altas taxas de sucesso clínico, é imprescindível associar a esta técnica implantes com características de macro e micro/nanoestruturas adequadas, como o novo implante mostrado neste relato de caso.

\section{REFERÊNCIAS}

1. Visscher CM, Lobbezoo F, Schuller AA. Dental status and oral health-related quality of life. A population-based study. J Oral Rehabil. 2014 Jun;41(6):416-22.

2. Adell R, Lekholm U, Rockler B, Branemark PI. A 15-year study of osseointegrated implants in the treatment of the edentulous jaw. Int $\mathrm{J}$ Oral Surg. 1981 Dec;10(6):387-416.

3. Hämmerle CHF, Chen ST, Wilson TG Jr. Consensus statements and recommended clinical procedures regarding the placement of implants in extraction sockets. Int $\mathrm{J}$ Oral Maxillofac Implants. 2004;19 Suppl:26-8.

4. Ragucci GM, Elnayef B, Criado-Cámara E, Del Amo FS-L, Hernández-Alfaro F. Immediate implant placement in molar extraction sockets: a systematic review and meta-analysis. Int $\mathrm{J}$ Implant Dent. 2020;6:40.

5. Lang NP, Pun L, Lau KY, Li KY, Wong MCM. A systematic review on survival and success rates of implants placed immediately into fresh extraction sockets after at least 1 year. Clin Oral Implants Res. 2012;23 Supp1 5:39-66.

6. Sanz M, Cecchinato D, Ferrus J, Salvi GE, Ramseier C, Lang NP, et al. Implants placed in fresh extraction sockets in the maxilla: clinical and radiographic outcomes from a 3-year follow-up examination. Clin Oral Implants Res. 2014;25(3):321-7.

7. Atieh MA, Payne AGT, Duncan WJ, Silva RK, Cullinan MP. Immediate placement or immediate restoration/loading of single implants for molar tooth replacement: a systematic review and metaanalysis. Int J Oral Maxillofac Implants. 2010;25(2):401-15.

8. Fugazzotto PA. Implant placement at the time of maxillary molar extraction: treatment protocols and report of results. J Periodontol. 2008;79(2):216-23.

9. Fugazzotto PA. Implant placement at the time of mandibular molar extraction: description of technique and preliminary results of 341 cases. J Periodontol. 2008;79(4):737-47.

10. Bianchi AE, Sanfilippo F. Single-tooth replacement by immediate implant and connective tissue graft: a 1-9-year clinical evaluation. Clin Oral Implants Res. 2004;15(3):269-77.

11. Goiato MC, Santos DM, Santiago JF Jr., Moreno A, Pellizzer EP. Longevity of dental implants in type IV bone: a systematic review. Int J Oral Maxillofac Surg. 2014;43(9):1108-16.

12. Deporter D. Dental implant design and optimal treatment outcomes. Int J Periodontics Restorative Dent. 2009;29(6):625-33.

13. Leonhardt A, Gröndahl K, Bergström C, Lekholm U. Long-term follow-up of osseointegrated titanium implants using clinical, radiographic and microbiological parameters. Clin Oral Implants Res. 2002;13(2):127-32.

14. Meredith N. Assessment of implant stability as a prognostic determinant. Int J Prosthodont. 1998;11(5):491-501.

15. Lozano-Carrascal N, Salomó-Coll O, Gilabert-Cerdà M, FarréPagés N, Gargallo-Albiol J, Hernández-Alfaro F. Effect of implant macro-design on primary stability: A prospective clinical study. Med Oral Patol Oral Cir Bucal. 2016;21(2):e214-21.

16. Chávarri-Prado D, Brizuela-Velasco A, Diéguez-Pereira M, Pérez- 
Pevida E, Jiménez-Garrudo A, Viteri-Agustín I, et al. Influence of cortical bone and implant design in the primary stability of dental implants measured by two different devices of resonance frequency analysis: an in vitro study. J Clin Exp Dent. 2020;12(3):e242-8.

17. Valenzuela S, Olivares JM, Weiss N, Benadof D. Immediate implant placement by interradicular bone drilling before molar extraction: clinical case report with one-year follow-up. Case Rep Dent. 2018.

18. Scarano A, Carinci F, Quaranta A, Iezzi G, Piattelli M, Piattelli A. Correlation between implant stability quotient (ISQ) with clinical and histological aspects of dental implants removed for mobility. Int J Immunopathol Pharmacol. 2007;20(1 Suppl 1):33-6.

19. Rebele SF, Zuhr O, Hurzeler MB. Pre-extractive interradicular implant bed preparation: case presentations of a novel approach to immediate implant placement at multirooted molar sites. Int J Periodontics Restorative Dent. 2013;33(1):89-96.

20. Davarpanah M, Szmukler-Moncler S. Unconventional implant treatment: I. Implant placement in contact with ankylosed root fragments. A series of five case reports. Clin Oral Implants Res. 2009;20(8):851-6. 